1 Davis MJ, Cilo M, Plaitakis A, Yahr MD. Trichinosis: severe myopathic involvement with recovery. Neurology 1976;26:37-40.

2 Gross B, Ochoa J. Trichinosis: clinical report and histochemistry of muscle. Muscle Nerve 1979;2:394-8.

3 Banker BQ. Parasitic Myositis. In: Engel AG, Banker BQ, eds Myology. Basic and clinical. New York: McGraw-Hill, 1986:1467-99.

4 Rose AL, Willison RG. Quantitative electromyography using automatic analysis: studies in healthy subjects and patients with primary muscle disease. $J$ Neurol Neurosurg Psychiatry 1967;30:403-10.

5 Stålberg E, Trontelj J. Single Fibre Electromyography. Old Woking, Surrey: Mirvalle Press, 1979.

6 Hilton-Brown P, Stålberg E, Osterman PO. Signs of reinnervation in myasthenia gravis. Muscle Nerve 1982;5:215-21.

7 Henriksson KG, Stälberg E. The terminal innervation pattern in polymiositis: a histochemical and SFEMG study. Muscle Nerve 1978;1:3-13.

Accepted 12 December 1988

\section{Dissecting aneurysm of middle cerebral artery} following resection of meningioma

Sir: Dissecting aneurysms of the intracranial arteries are rare. Spontaneous dissecting aneurysms have been reported in patients with arterial hypertension, cystic media degeneration, fibromuscular dysplasia, and in cases of Marfan's syndrome. ${ }^{12}$ Blunt skull trauma may also lead to defects of the internal elastic membrane of intracranial vessels, but there is always the possibility of preexisting vascular lesions. ${ }^{2}$ We present a case of post-traumatic dissecting aneurysm following partial resection of a large sphenoid ridge meningioma.

A 49 year old patient was admitted for the removal of a large meningioma. CT showed a tumour of the right sphenoid wing measuring $3.5 \times 4 \mathrm{~cm}$, with a $0.5 \mathrm{~cm}$ shift of the midline structures to the left. In preoperative angiography there was distension of the carotid siphon and the circle of Willis. The M1 sector of the ipsilateral middle cerebral artery was stenosed. At operation, the tumour was found surrounding the M1, M2, and M3 segment of the middle cerebral artery and the proximal segments of the anterior and communicans posterior arteries. Partial resection of the tumour was performed, leaving some surrounding the medial cerebral artery, which was seen pulsating during the operation. Twenty four

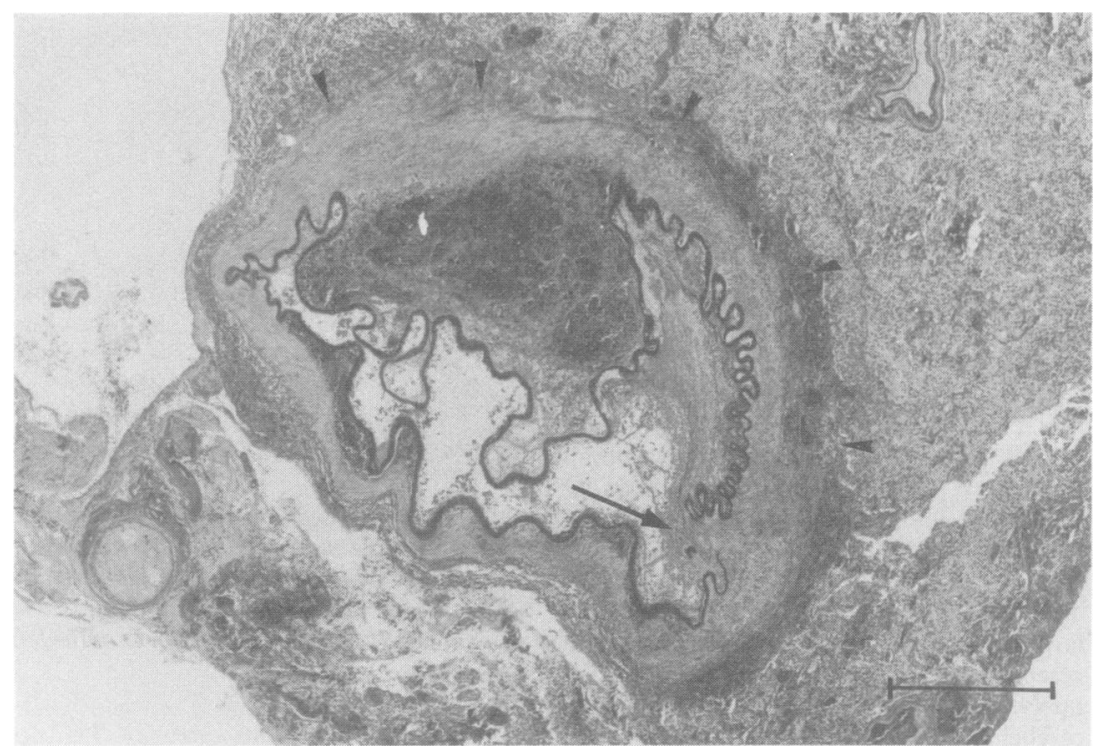

Fig Cross-section of the middle cerebral artery with perivascular tumour fragments. The adventitial tissue is intimately connected with tumour stroma (arrow heads). A haemorrhage is situated underneath the internal elastic membrane. The large arrow indicates the defect in the internal elastic membrane. (Elastic van Gieson stain, bar $=50 \mu \mathrm{m}$.) hours after surgery, CT showed a slight hypodensity in the right temporal lobe. Three days after operation a large infarct in the area of the right middle cerebral artery was diagnosed by CT. The patient died on day 6 after surgery.

A large, approximately 5 day old infarct of the middle cerebral artery was found at postmortem examination. Small tumour fragments were still attached to the vessel wall. Histologically, an endotheliomatous meningioma had invaded the wall of the middle cerebral artery. There were multiple ruptures of the internal elastic membrane along a $5 \mathrm{~mm}$ segment, with underlying haematoma (fig). Some granulation tissue and iron-positive macrophages at the border of the haematoma were found. The other arteries were free of degenerative changes.

Some cases of dissecting aneurysms of intracranial arteries had recent head trauma, in other cases a generalised vasculopathy was observed. ${ }^{1-4}$ In our case, this was clearly absent; all other vessels were free of pathological changes. The resection of a tumour intimately connected to the vessel wall appears to be the only plausible explanation for this dissecting aneurysm. In one previous case $^{5}$ a dissecting aneurysm was considered to be directly related to surgery and occurred after resection of an aneurysm of the middle cerebral artery. This is the first instance reported after surgery for a brain tumour. NORBERT HEYE

JOSE R IGLESIAS HANS HENKES RON FERZST KLAUS MAIER-HAUFF Institute of Neuropathology, Neurosurgery, Psychiatry and Radiology, Klinikum Steglitz and Klinikum Westend, Freie Universität Berlin, Hindenburgdamm 30 ,

\section{References}

1 O'Connell BK, Towfighi J, Brennan RW, et al. Dissecting aneurysms of the head and neck. Neurology 1985;35:993-7.

2 Krauland W. Verletzungen der Intrakraniellen Schlagadern. Berlin: Springer, 1982:125-40.

3 Farrell MA, Gilbert JJ, Kaufmann JCE. Fatal intracranial arterial dissection: clinical pathological correlation. J Neurol Neurosurg Psychiatry 1985;48:111-2.

4 Morki B, Sundt TM, Houser OW, Piepgras DG. Spontaneous dissection of the cervical internal carotid artery. Ann Neurol 1986;19:126-38.

5 Bigelow NH. Intracranial dissecting aneurysms. Arch Pathol 1955;60:271-5.

Accepted 5 November 1988 1000 Berlin, FRG. 